Cahiers $d u$ MONDE RUSSE

\section{Cahiers du monde russe}

Russie - Empire russe - Union soviétique et États indépendants

$43 / 4 \mid 2002$

Intellectuels et intelligentsia

\title{
Martine Mespoulet, Statistique et révolution en Russie
}

\section{Cécile Lefèvre}

\section{OpenEdition \\ Journals}

Édition électronique

URL : https://journals.openedition.org/monderusse/4017

DOI : 10.4000/monderusse.4017

ISSN : $1777-5388$

Éditeur

Éditions de l'EHESS

\section{Édition imprimée}

Date de publication : 30 décembre 2002

Pagination : 699-701

ISBN : 2-7132-1796-2

ISSN : $1252-6576$

Référence électronique

Cécile Lefèvre, "Martine Mespoulet, Statistique et révolution en Russie », Cahiers du monde russe [En ligne], 43/4 | 2002, mis en ligne le 17 juin 2009, consulté le 03 septembre 2022. URL : http:// journals.openedition.org/monderusse/4017; DOI : https://doi.org/10.4000/monderusse.4017

Ce document a été généré automatiquement le 3 septembre 2022

Tous droits réservés 


\title{
Martine Mespoulet, Statistique et révolution en Russie
}

\author{
Cécile Lefèvre
}

\section{RÉFÉRENCE}

Martine MESPOULET, Statistique et révolution en Russie. Un compromis impossible (1880-1930). Rennes, Presses Universitaires de Rennes, 2001, 338 p.

1 L'ouvrage de Martine Mespoulet retrace d'abord et avant tout l'histoire d'une profession, celle de statisticien, qui se constitue après les grandes réformes administratives de 1864 . Ces dernières instaurent la création des zemstva, ou assemblées provinciales élues, dotées d'un certain nombre de compétences économiques et sociales, et devant à ce titre développer une fiscalité locale et disposer d'indicateurs statistiques pour la mise en œuvre de leurs politiques. Ce contexte, conjugué à la condamnation à l'exil intérieur dans les villes de province de nombreux intellectuels diplômés, fut un terreau propice à la professionnalisation du métier de statisticien par constitution d'une éthique et d'un projet communs à travers le réseau des bureaux de statistique des zemstva.

2 Mais l'intérêt de l'ouvrage ne réside pas seulement dans cette étude détaillée de sociologie des professions. C'est l'histoire politique et sociale de la Russie qui est réinterrogée, et notamment celle des relations entre administration et pouvoir politique, dans une approche renouvelée de la périodisation de l'histoire russe, en déployant l'histoire de cette profession de la fin de la période tsariste jusqu'aux années 1930.

Cette étude s'attachant au parcours des hommes tout autant qu'à leurs pratiques et qu'aux débats scientifiques et politiques qui ont modelé leurs activités de statisticiens a été largement permise par l'ouverture des archives, et notamment des archives régionales. Le choix d'étudier plus particulièrement un bureau provincial de statistique, celui de Saratov, ville importante de la Volga, démontre brillamment tout l'intérêt de s'y pencher. 
Il s'agit enfin d'une contribution importante à l'histoire de la statistique, dans la lignée des travaux d'Alain Desrosières, où l'histoire des institutions, celle des hommes et des techniques se mêlent étroitement. Il apparaît ainsi nettement que, jusqu'aux années 1920, les statisticiens russes étaient très présents dans les discussions scientifiques internationales et qu'ils avaient été amenés très tôt, et par des confrontations permanentes entre la théorie et la pratique, à développer les premières enquêtes par sondage.

Dans une première partie, qui couvre une période allant des années 1880 jusqu'à la révolution de 1917, Martine Mespoulet retrace donc la naissance d'un profession, celle de statisticien des zemstva. Réformes décentralisatrices, développement d'idées réformatrices au sein d'un milieu d'intellectuels en exil intérieur, demande politique et sociale d'indicateurs statistiques conduisent conjointement à la «formation d'un nouveau corps de professionnels». C'est la grande période d'innovation dans les méthodes d'enquêtes et techniques statistiques, ainsi que de consolidation des acquis de la profession à travers le développement de la formation. Particulièrement intéressants sont ainsi les développements sur la genèse des enquêtes par sondage et les questionnements des statisticiens sur les notions d'unité d'observation et de représentativité.

6 La Première Guerre mondiale constitue une étape importante, avant même la révolution, pour une réflexion des statisticiens sur le développement d'une statistique d'État. Il s'agit pour eux d'un projet scientifique, dominé par une pensée sociale, qui doit œuvrer au développement de l'État gestionnaire, mais en toute indépendance, « au service de la vérité ». Cette statistique d'État ne prendra a posteriori pas la forme souhaitée par ces statisticiens, mais les années 1919-1924 semblent être encore à leurs yeux une occasion de développer leur projet, à l'origine d'une incompréhension puis de conflits entre statisticiens et dirigeants bolcheviks. Dans cette seconde partie de l'ouvrage, la transformation de la statistique aux débuts des années 1920 dans le cadre du nouveau pouvoir bolchevik est ainsi étudiée finement à travers les évolutions de la structure de son personnel, de sa qualification, et des formations de statistique. Et ce regard particulier apporte une profondeur et une complexité humaine à l'évocation des bouleversements politiques de cette période.

7 Avec les premières purges, et la tutelle grandissante de la Commission d'État au Plan (le Gosplan), ce que Martine Mespoulet appelle «la défaite d'une profession» se dessine. La dernière partie est alors consacrée à la mise sous surveillance, progressive et inéluctable, de la profession de statisticien. Ceci passe à la fois par des changements fréquents de personnel à la direction de la statistique, par un contrôle étroit exercé sur la formation professionnelle, par la fermeture des bureaux de statistique des gubernii, par un processus de déqualification, et par la mise en concurrence puis sous tutelle du Plan. Tous les éléments sont réunis pour marquer la dépossession d'une profession de la statistique telle qu'elle la concevait, tandis que peut se mettre en place une statistique soviétique ou plutôt une comptabilité tout instrumentale, au service du politique et de la planification économique.

8 Au carrefour de l'histoire de la statistique, de la sociologie des professions et de l'histoire sociale de la Russie, cet ouvrage constitue donc une contribution novatrice aux travaux consacrés depuis l'ouverture des archives russes au rôle des hommes - ici une génération de «spécialistes bourgeois ", les statisticiens - à la fois dans l'expérience des zemstva et 
leur impact sur le développement régional avant la Première Guerre mondiale, et dans la formation de l'État soviétique. 